\title{
APROXIMACIONES A LA GENEALOGÍA EN EL ESTUDIO DEL ENTORNO URBANO. LOS TRES ENFOQUES
}

Navarrete-Valencia, Luis; Flores-Rodríguez, Carlos E.

APROXIMACIONES A LA GENEALOGÍA EN EL ESTUDIO DEL ENTORNO URBANO. LOS TRES ENFOQUES

Revista Legado de Arquitectura y Diseño, vol. 15, núm. 27, 2020

Universidad Autónoma del Estado de México, México

Disponible en: http://www.redalyc.org/articulo.oa?id=477963263007

Esta obra está bajo una Licencia Creative Commons Atribución-NoComercial-SinDerivar 4.0 Internacional. 


\title{
APROXIMACIONES A LA GENEALOGÍA EN EL ESTUDIO DEL ENTORNO URBANO. LOS TRES ENFOQUES
}

\author{
GENEALOGY APPROACHES IN THE STUDY OF THE \\ URBAN ENVIRONMENT. THE THREE APPROACHES \\ Luis Navarrete-Valencia navarreteluis@yahoo.com \\ Universidad Autónoma de Nayarit, México \\ Carlos E. Flores-Rodríguez fcarlose@gmail.com \\ Universidad Autónoma de Nayarit, México
} Revista Legado de Arquitectura y Diseño,
vol. 15, núm. 27, 2020

Universidad Autónoma del Estado de México, México

Recepción: 10 Octubre 2019 Aprobación: 11 Diciembre 2019

Redalyc: http://www.redalyc.org/ articulo.oa?id $=477963263007$
Resumen: Hablar de ciudad es aludir lo material, lo cultural, lo natural y lo social, como aspectos constitutivos del entorno urbano; concepto complejo, cuyo entendimiento ha atraído la atención de distintas disciplinas. Sin embargo, es precisamente esta diversidad en el linaje académico, lo que ha impedido su construcción como objeto y categoría de estudio definida. Ante ello, a partir de una consulta documental, sistemática y organizada, en el presente trabajo se analizan algunos de los referentes más relevantes que han estudiado a la ciudad y su entorno con el objetivo de visibilizar las distintas posturas, enfoques, teorías y métodos con los que se han conducido, y así establecer su genealogía. ${ }^{[1]}$

Aunque dicha genealogía es poco definida, se dice que los referentes - provenientes de la Arquitectura, el Urbanismo, la Antropología Cultural y la Geografía Humana-, se clasifican según tres enfoques: el ecológico ambiental, el paisajístico perceptivo y el antropológico cultural, que además representan tres momentos a lo largo del siglo pasado y lo que va de éste. Se observa que, directa o indirectamente, los planteamientos coinciden con los establecidos por Patrick Geddes, que luego de un siglo continúan vigentes. Por último, se advierte la factibilidad y pertinencia de estudiar la ciudad y su entorno desde aproximaciones interdisciplinares, cuyos cruces metodológicos posibiliten el acceso a renovadas explicaciones y comprensiones de la realidad social y urbana.

Palabras clave: categoría, ciudad, epistemología, Geddes, paisaje.

Abstract: Talking about cities means alluding to the material, cultural, natural and social, aspects that are all part of the urban environment, and it is a complex concept. Its understanding has attracted the attention of different disciplines. However, it is precisely this diversity in the academic lineage that has prevented its construction as a defined object and category of study. Due to this, from a systematic and organized documentary consultation, this work analyzes some of the most relevant references that have studied the city and its environment with the intention of looking at the different positions, approaches, theories and methods used, and thus establish its genealogy.

Although it is identified that this genealogy is poorly defined, it is found that the referents - mainly from Architecture, Urbanism, Cultural Anthropology and Human Geographycan be classified according to three approaches: the ecological-environmental, the perceptual landscape and the anthropological-cultural, that also represent three moments throughout the last century and what goes of it. It is also observed that, directly or indirectly, the approaches coincide with those established by Patrick Geddes, which after a century are still in force. Finally, it is noted that the feasibility and relevance of studying the city and its surroundings from interdisciplinary approaches with methodological crossings, allow access to renewed explanations and understandings of social and urban reality.

Keywords: category, city, epistemology, Geddes, landscape. 


\section{INTRODUCCIÓN}

El entorno, entendido como el conjunto de elementos y aspectos que rodean a algo, es un concepto genérico, cuya abstracción permite dar cabida a acepciones como las de espacio, lugar, ambiente o paisaje, entre otras, lo cual resulta conveniente en trabajos exploratorios como el que se presenta. En la búsqueda de su definición y análisis es necesario agregarle elementos de relación, en este caso, la ciudad y la sociedad. Así, se construye el concepto de entorno urbano, que considera tanto a las construcciones y artificios, como a los elementos naturales, culturales y sociales con que coexiste, y en referencia a la espacialidad y a la temporalidad en que se produce.

En la pluralidad de estudios sobre el entorno urbano, el objeto en común es la ciudad, cuyas características de aleatoriedad e irreversibilidad la hacen única e irrepetible (Ruíz, 2000). Luego del llamado método científico, se creyó que los modos de estudiarla tenderían a homogeneizarse, pero no fue así. Contrariamente, su definición y entendimiento ha sido una tarea diferenciada, ejercida desde distintos enfoques y campos del conocimiento. Aunque ha prevalecido una visión cientificista y utilitaria, a partir de la segunda mitad del siglo $\mathrm{XX}$, impulsadas sobre todo por los giros culturales y lingüísticos, surgirían propuestas alternativas enfocadas en categorías menos fácticas relacionadas a lo social, lo cultural y lo simbólico de la ciudad.

Sin embargo, la genealogía de estas propuestas es poco clara y de difícil clasificación, principalmente por su tradición romanticista y origen multidisciplinar. Eso ha impedido determinar los límites y alcances de sus posturas, métodos y categorías de análisis lo que, consecuentemente, ha participado en la incertidumbre en su construcción como objeto de estudio y episteme de sustento. Ante tal condición, el objetivo de este trabajo es analizar algunos de los referentes más relevantes que han estudiado a la ciudad y su entorno con la intención de visibilizar, precisamente, las distintas posturas y aproximaciones teóricas y metodológicas con las que se han conducido. Para ello, en términos de método, a partir de diversas fuentes (libros, artículos científicos, tesis, etc.) se hace consulta documental, sistemática y organizada, de forma transversal y longitudinal.

Derivado de este ejercicio, de suyo dialéctico, un primer hallazgo no sólo exhibe el carácter del abordaje, sino que se utiliza como estructura del estudio. Antes, se realiza una breve reflexión sobre la ciudad y su entorno, con sus consideraciones de acercamiento epistémico y disciplinar. Después se exponen las propuestas y sus autores clasificándolos en tres grupos de acuerdo con su enfoque particular: los estudios con enfoque ecológico ambiental (de base cartesiana); los trabajos paisajísticos perceptivos (de base fenomenológica); y los referentes con enfoque antropológico cultural (de base hermenéutica o interpretativa). Tras el análisis, las propuestas y planteamientos son discutidos para, finalmente, establecer nuevas generalizaciones a manera de hallazgos o conclusiones. 


\section{CONSIDERACIONES PREVIAS SOBRE LA CIUDAD}

Según Bochenski (1997) son dos las grandes fuentes filosóficas del pensamiento occidental que han permeado hasta nuestros días en cualquier debate, entre ellos el de la ciudad. Luego de que ambas adoptaran como basa al evolucionismo darwinista su posible separación se redujo, aunque eso no impidió conservar una clara diferencia entre ellas. El romanticismo plantearía que otras teorías y explicaciones son posibles, lo cual daría cabida a que lo urbano pudiera ser interpretado desde la tradición epistémica fenomenológica, hermenéutica y lingüística. El idealismo kantiano, por su parte, tomaría la postura epistémica empíricoanalítica para estudiar a los hechos urbanos, que deberían verse como artefactos técnicos y medibles (García, 2016; Mardones, 2003).

Aymonino (1971) asegura que sería la Revolución Industrial de donde surgirían los fenómenos que afectarían a la ciudad occidental establecida. Enmarcadas en asuntos de higienismo, también desde ahí surgirían -o se consolidarían- las tres rutas que, hasta nuestros días, buscarían restaurar o restablecer ese orden perdido y que, básicamente, se centrarían en la relación de la ciudad con su entorno, marcadamente el natural (Flores, 2015a). De esas tres rutas, la societaria sería, y a partir de sus críticas, denuncia social y propuestas teóricas, la que tomaría al fenómeno urbano como objeto de análisis y conceptualización con carácter cientificista. Es decir, lo urbano sería visto como pensamiento social en cualquiera de las tradiciones y posturas epistémicas de las Ciencias Sociales y Humanas, lo que se vería reflejado, a su vez, en los tres enfoques aquí propuestos (Wallerstein, 2007; Collins, 1996).

Concretamente a la relación de la ciudad con su entorno, lo más cercano ha sido su tratamiento como paisaje. Souto (2011) lo propone como un concepto polisémico, originario de la geografía clásica, y que está dotado de abordajes y utilizaciones que irían desde lo estético, hasta emplearlo como categoría científica por la Geografía Cultural que lo interpreta como una cualidad cultural y simbólica: el paisaje tendrá sentido siempre que se le relacione con la sociedad que lo utiliza e interiorice. La apropiación del término por la Geografía, no obstante, no está del todo claro. García (2014) lo describe asociándolo a la Sociología. Desde Durkheim hasta Giddens, dice, serían sus trabajos los que habrían de inspirar a los geógrafos transitando, de nuevo, de los descriptivos hasta aquellos que ven al sujeto como el dador de significados.

En todo caso hay un intento por estudiar conjuntamente lo social con lo geográfico, y viceversa, de lo que surgiría la sociografía o Geografía Social, no quedando muy claro si es la Geografía la que incorpora a las teorías sociales, o son los sociólogos los que incorporan las categorías espaciales o territoriales. Para Hiernaux (2010) este encuentro no se trata sino de giros, en este caso, el giro espacial o geográfico, a partir del cual las Ciencias Sociales han integrado categorías espaciales en sus estudios, particularmente, el sentido de lugar asociado al paisaje. Esto desde una discusión también común: la ontología de quien le da sentido a tal espacio. Como sea, se parte del supuesto que sería la Urbanística, en cualquiera 
de sus tres rutas, en su incapacidad de generar un discurso teórico propio, la disciplina que mayormente utilizaría estos marcos de pensamiento en su búsqueda de entendimiento, gestión, modelización e incidencia en fenómenos complejos como lo son, por definición, los de la ciudad (Flores, 2015b).

\section{ENFOQUE ECOLÓGICO AMBIENTAL. LO CARTESIANO INDIVIDUAL}

Como se ha planteado, la Revolución Industrial trajo efectos que suscitaron problemas ambientales y urbanos hasta antes inexistentes. El método científico se apropia de una emergente ciencia urbana estableciéndose como inequívoco modo de respuestas a estos problemas de la ciudad (Sica, 1980; Terán, 1985). Bajo ese ambiente, como una reacción, se comenzó a cuestionar la relación de la ciudad con su entorno. Tratando de superar la visión dicotómica marxista, hasta ese momento hegemónica -donde el campo y la ciudad están en constante tensión-, surgen las propuestas de base culturalista en las cuales dicha relación se vería en complementariedad, siempre mediadas bajo la matriz de la sociedad (Bettin, 1983; Bassols, 1988; Urrutia, 1999).

Aunque su personalidad epistémica es imprecisa, uno de los pioneros en el estudio de la ciudad es Geddes (1960). De corte darwinista, a principios del siglo pasado hace una analogía al comparar a la ciudad con un organismo vivo, pues dice que los procesos sociales que la conforman se mantienen en evolución. Consiguientemente, recomienda estudiar su proceso histórico (evolutivo), para así comprender su presente (paleotécnico) y visualizar su futuro (neotécnico). Este geógrafo inglés se convertiría en referente de la genealogía de los estudios urbanos pues, entre otras cosas, sería el primero en proponer la utilización de metodologías etnográficas y participativas en el análisis y planificación de la ciudad, al afirmar que ésta debe ser entendida desde la diversidad de experiencias de las personas que la viven y no sólo desde la visión de los especialistas.

Años después, en la década del sesenta del siglo pasado, McHarg (2000) en cierta medida, viene a refrescar y operacionalizar algunos de los planteamientos hechos por Geddes. Posicionado desde la Ecología, representa uno de los primeros intentos por fusionar lo natural con lo humano, al proponer estudiar interdisciplinarmente la relación entre los sistemas biofísicos y los sistemas sociales, con lo cual da paso a la Ecología Humana; sin embargo, en su obra, el componente social es subsumido de manera determinista por lo ecológico-ambiental. De tradición chicaguense, como parte de su método utiliza mapas que, al ser superpuestos, permiten visualizar relaciones y cruces de información que difícilmente podrían ser detectados mediante otras herramientas.

Por ese mismo tiempo, Olgyay (1998) establece las bases de la Arquitectura y el Urbanismo Bioclimático. Bajo una visión cientificista, analiza las relaciones que se establecen entre las edificaciones y las condiciones climáticas. Explica que se ha desatendido la variable climática 
al momento de diseñar y planificar, lo cual ha derivado en inadecuadas intervenciones arquitectónicas y urbanas. A cambio, sugiere estudiar a la ciudad desde principios y leyes físicas con métodos y técnicas provenientes de la Biología, la Meteorología y la Ingeniería, entre otras ciencias duras. Es una postura del modernismo, de pretensiones universalistas, pues considera que los criterios y estudios de diseño bioclimático pueden ser replicados en otras partes del mundo.

Los aportes de Olgyay (1998), McHarg (2000) e indirectamente de Geddes (1960), han influido en el quehacer de otros autores, así como en la legislación de habla hispana. El caso de Fariña (2007) puede ser referencial, ya que es responsable de una serie de textos en los que lo natural es abordado desde este enfoque cartesiano. Desprendido de esta tradición, Higueras (2012) propone al Urbanismo bioclimático. Asimila al entorno urbano como objeto factible de medirse con instrumentos físicos (de laboratorio), con lo cual se obtienen datos e información que puede ser utilizada como medio para incidir en las ordenanzas ambientales, urbanísticas y territoriales.

Así es como los trabajos ecológicos ambientalistas, de tradición darwinista y fundamentados en el método científico, emergerían en este intento por paliar algunos de los problemas socioambientales originados por la industrialización y urbanización crecientes.

\section{ENFOQUE PAISAJÍSTICO PERCEPTIVO. LO FENOMÉNICO INDIVIDUAL}

En la búsqueda de renovadas formas de estudiar al entorno urbano, durante la segunda mitad del siglo XX, algunos autores se propusieron abordarlo desde la percepción y la subjetividad. Uno de ellos fue Lynch (1998), quien en la década del sesenta del siglo referido sentó un precedente al estudiar sistemáticamente la imagen de la ciudad, la cual, dice, al "estar embebida de recuerdos y significados", representa un vínculo entre las personas y la ciudad (Lynch, 1998: 9). Se trata de una relación determinista, donde las percepciones, conductas y acciones, dependen de las condiciones materiales del entorno urbano. Así es como el autor aporta el concepto de "imaginabilidad", definida como la "cualidad de un objeto físico que le da una gran probabilidad de suscitar una imagen vigorosa en cualquier observador de que se trate" (Lynch, 1998: 19).

Cullen (1974), por su parte, considera que es un genuino placer visual y estético el acto de vivir en la ciudad. Por eso mismo la percibe como objeto -estético-, a la vez que se interesa por estudiar el "arte del paisaje" urbano (Cullen, 1974: 193). Su posicionamiento es antagónico al de los planificadores tecnócratas de la ciudad, ya que mientras ellos propugnan canónicamente por trazas ortogonales, calles rectas y una imagen urbana homogénea y ordenada, él propone conservar en la ciudad esas "mezclas de estilos, materiales y proporciones, [pues] constituyen su principal encanto", además de que son fuente de identidad y sentido (Cullen, 1974: 11). Aunque menciona que el entorno urbano puede estudiarse mediante 
el análisis de las percepciones, en la práctica ello se circunscribe a sus propias percepciones y no a las de quienes viven la ciudad.

Estas sensaciones y percepciones del entorno serían categorizadas por Tuan (2007) como "topofilia", entendida como el "lazo afectivo entre las personas y el lugar o el ambiente circundante" (Tuan, 2007:13). Con ello, el autor asume que las relaciones entre las personas y el entorno se establecen a partir de las percepciones, actitudes y valoraciones, por lo que deben estudiarse como un todo, para saber cómo es que mutuamente se influyen o determinan, por lo que habrá de atenderse sistemáticamente, y no sólo desde la intuición, pues según dice, "los hallazgos sistematizados son de inestimable valor porque dan precisión a las corazonadas del sentido común" (Tuan, 2007: 12).

Bailly (1978) también otorga especial atención a la dimensión perceptiva del entorno, lo que propone es "llegar a conocer, en sus diversas escalas y por medio de distintos métodos, el modo cómo es percibida y vivida la ciudad", un enfoque que, asegura, ha sido "poco utilizado en Urbanismo y en Geografía” (Bailly, 1978: 24). Afirma también, que la diferenciada recepción de estímulos durante el proceso perceptivo media para que el individuo forje, o no, vínculos subjetivos con el entorno y construya el (su) sentido de lugar, además de condicionar sus actos y conductas.

Semejando a Bailly (1978), pero ya en el presente siglo, Maderuelo (2010) asegura que para comprender el paisaje habrá que interpretar las percepciones de la gente, las cuales están determinadas por factores físicos, estéticos y "emocionales, que tienen que ver con la formación cultural y con los estados de ánimo de quienes [lo] contemplan" (Maderuelo, 2010: 576). Dice, además, que la carencia de identidad en las ciudades actuales se debe, en gran medida, a que en los procesos de planificación no son considerados "los anhelos y necesidades vitales de los ciudadanos [lo cual] no contribuye a la formación de un paisaje cotidiano que logre expresar lo que de particular anida en el carácter de la colectividad" (Maderuelo, 2010: 598).

Sobre el concepto de paisaje urbano, Zoido (2012) advierte a no confundirlo con otros como los de imagen o morfología urbana. Aclara que para poder hablar de paisaje urbano es indispensable estudiar el espacio vivido, lo cual se logra desde el análisis de las prácticas de los habitantes, así como desde las percepciones y valoraciones sociales, que "encuentran su raíz en razones culturales" y atribuyen al paisaje significados, tanto utilitarios como simbólicos (Zoido, 2012: 20). Acorde con eso, metodológicamente Careri (2013) incita a salir a la calle y caminar por la ciudad, ya que así es posible identificar las "categorías con las cuales interpretamos los paisajes urbanos" (Careri, 2013: 15). Además de que la práctica del andar, afirma, "es un instrumento estético capaz de describir y de modificar aquellos espacios metropolitanos que a menudo presentan una naturaleza que debería comprenderse y llenarse de significados, más que proyectarse y llenarse de cosas" (Careri, 2013: 20).

Bajo un matiz antropológico, Thiébaut (2013) considera al entorno como paisaje cultural, construido desde la relación que se establece entre 
lo funcional, lo simbólico y lo identitario. Propone llevar a cabo estudios comparativos entre el pasado y el presente para detectar los cambios que se han suscitado en el paisaje. Metodológicamente hace revisiones documentales históricas, e inmersiones antropológicas con la aplicación de técnicas etnográficas. Así son identificadas las percepciones y los usos que se realizan en el entorno, como medio para conocer los efectos que la transformación paisajística tiene en la construcción identitaria y simbólica de los habitantes.

De manera similar a Thiébaut (2013), Alberto-Villavicencio (2017) hace un aporte desde la Geografía cultural y Geografía de las emociones. Fundamentada en Berque, quien considera al paisaje como una "'entidad medial' entre la sociedad y su entorno natural" (2014, en AlbertoVillavicencio, 2017:35), la autora propone estudiar al objeto desde categorías como las de memoria, percepción y emoción. Mediante las técnicas de historia de vida y análisis documental, analiza las relaciones históricas que los individuos han establecido con el paisaje, tanto en su dimensión natural como simbólico-cultural.

Precisamente esta relación entre cultura y naturaleza es abordada por D’Hers (2017), quien estudia la relación entre la ciudad y los elementos naturales con los que coexiste. Uno de sus supuestos es que en las ciudades el protagonismo generalmente se lo llevan los objetos y creaciones culturales, como son los edificios y monumentos, y que sólo en pocos casos un elemento natural es más importante. Para ponerlo en práctica, mediante los imaginarios del paisaje y el método etnográfico, el autor explora las percepciones y significaciones, así como los dispositivos culturales que contribuyen a la conformación de la identidad asociada a la ciudad y a los elementos naturales.

Por último, Monnet (1995) hace una reflexión sobre el concepto de lugar. Distintivamente, para definirlo recurre a la locución latina de locus que, asegura, no refiere propiamente a valores del espíritu del lugar, tal como asegura Rossi (1981) -o el propio Norberg-Schulz (1976) y sus tres interpretaciones al concepto romano de Genius Loci-, sino que su interiorización obedece al modo en que cada habitante vive y percibe determinado lugar. Por eso mismo, el locus tendría variantes dependiendo de la referencia de interacción. Ramos (2018), por ejemplo, propone llamar extralocus a la visión que se tiene del paisaje exterior desde dentro de la ciudad, e intralocus a la imagen construida hacia y desde el interior de ella.

Como ha sido expuesto, los referentes que constituyen el enfoque paisajístico perceptivo se presentan como una segunda ola, en cierta forma, reaccionarios al cientificismo dominante. Son propuestas que se fundamentan en la fenomenología y consideran al entorno como paisaje, bajo el precepto de que éste puede ser percibido e interpretado con prelación hacia lo individual, lo subjetivo y lo ontológico. 


\section{ENFOQUE ANTROPOLÓGICO CULTURAL. LO HERMENÉUTICO COLECTIVO Y DIVERSO}

Por la complejidad que representa, lo urbano sería tratado a finales del siglo pasado desde su gran diversidad. Por lo mismo, se piensa la utilización de métodos, instrumentos, herramientas y estrategias pretendidamente novedosas en la búsqueda de otras interpretaciones y reconocimientos, así como de descripciones más profundas y diversas sobre la ciudad. Aunque tardíamente, la Antropología reconocería esa diversidad y relación del espacio, el tiempo y la sociedad. Sin suplir a la Sociología, esta Antropología de la ciudad -o de las sociedades-, irrumpe en esta discusión con las ya conocidas herramientas etnográficas (Cucó, 2014).

Desde esta Antropología, Geertz (1973) estudia al entorno en su dimensión cultural y simbólica. Para él, la cultura es una "trama de significación"; mecanismo de regulación normativo de la conducta que se traduce en acción social, en cuyo análisis no se buscan leyes sino desentrañar significados (Geertz, 1973: 20). En esa tarea, dice, el método etnográfico permite hacer interpretaciones o descripciones densas, para así descubrir el papel que juega la cultura en los procesos cotidianos y revelar el sentido que las personas otorgan al entorno y a las prácticas que allí realizan.

De Certeau (1996) abunda acerca de dichas prácticas en el espacio (entorno) y explica que muchas veces adquieren la connotación de tácticas. Éstas son definidas por el autor como "minúsculos y cotidianos procedimientos populares que organizan el orden sociopolítico [...], prácticas a través de las cuales los usuarios se reapropian del espacio organizado por los técnicos de la producción sociocultural" (De Certeau, 1996: 44). Metodológicamente, mediante la observación y análisis detallado habrá que identificar -apunta- los esquemas de operación y categorías comunes que permitan explicar las prácticas, pero, sobre todo, las astutas tácticas que los sujetos implementan en el entorno.

Giménez (2003), por su parte, estudia la forma en que la cultura y la identidad se relacionan dialécticamente con el entorno. Su principal argumento es que la identidad, mecanismo operador de diferenciación entre las personas, se construye en función de la cultura; es decir, es la cultura interiorizada por los sujetos para quienes el entorno y los objetos materiales juegan un papel importante. Así, el entorno natural se trasforma en cultural al construirse sobre un conjunto de significados, imágenes y símbolos, que en cierta medida son duraderos y compartidos socialmente.

Reguillo (1996) estudia conjuntamente las dimensiones material y simbólica de la ciudad. Analiza los modos en que distintos actores perciben, significan y actúan en la ciudad, de acuerdo con "mecanismos y mediaciones" reguladoras y condicionantes (Reguillo, 1996: 96). La autora hace distinción entre los saberes de los expertos y los de los ciudadanos comunes. Explica que ambos coexisten, aunque advierte que los primeros dominan e invisibilizan a los segundos. Es una relación 
desigual, pero estable, que se rompe cuando se entra en crisis ante ciertos acontecimientos disruptivos, donde lo primero que se altera son las rutinas de la vida cotidiana.

Quien también estudia antropológicamente a la ciudad es Duch (2015). Su reflexión es acerca de las relaciones que se dan entre naturaleza y cultura, y entre espacio y tiempo vividos, como aspectos constitutivos de una realidad urbana determinada, por lo que él llama transmisiones; es decir, factores que "constituyen las múltiples relaciones que se entretejen en la vida urbana de individuos y colectividades [sean éstas] de convivencia o malvivencia" (Duch, 2015: 25). Sugiere hacer una interpretación simultánea de lo material y lo inmaterial de la ciudad, pues si bien ésta se materializa sobre un estrato natural, es un elemento artificial e histórico conformado por relaciones determinadas culturalmente.

Acorde con esta línea interpretativa colectiva, Silva considera a la ciudad como el "lugar del acontecimiento cultural y como escenario de un efecto imaginario" (2006: 25). Dice que la ciudad es un objeto simbólico que "depende de las figuras que les da el pensamiento" (Silva, 2006: 92) y que puede ser conocido desde el "análisis práctico de los imaginarios urbanos" (Silva, 2006: 97). Explica que se trata de un proceso en donde primero se estudia la imagen de la ciudad, luego se identifican los usos sociales y expresiones urbanas, para finalmente recabar las representaciones mentales que elaboran las personas. Aquí se incluyen sensaciones, percepciones, memorias, deseos e incluso fantasías, con las cuales se construye la dimensión imaginaria de la ciudad.

Finalmente, Narváez (2011) plantea una alternativa para llevar a cabo estudios arquitectónico-urbanísticos. Con base en la Antropología, estudia cualitativa e interpretativamente a la ciudad desde el método etnográfico pues, asegura, éste "puede contribuir significativamente a revelar las sutiles relaciones que tienen lugar entre las formas sociales y las formas físicas construidas" (Narváez, 2011: 11); a la vez que recomienda, estudiar "paralelamente lo material objetivo y lo inmaterial subjetivo, como mitades complementarias de lo que denominamos realidad" (Narváez, 2011: 17).

Como se aprecia, los trabajos que integran el enfoque antropológico cultural se desarrollan sobre una línea hermenéutica o interpretativa. Esto a partir de descripciones densas e interpretaciones interiorizadas, y por ello más profundas, sobre los fenómenos sociales que, construidos colectivamente, ocurren en el entorno urbano. Con fines ilustrativos, los referentes analizados se muestran concentradamente en la figura 1. 


\begin{tabular}{|c|c|c|c|}
\hline $\begin{array}{l}\text { Postura } \\
\text { epistémica }\end{array}$ & Positivista & Fenomenológica & Hermenéutica \\
\hline Enfoque & \begin{tabular}{|l|} 
Ecológico \\
Ambiental \\
\end{tabular} & \begin{tabular}{|l|} 
Paisajístico \\
Perceptivo
\end{tabular} & $\begin{array}{l}\text { Antropológico } \\
\text { Cultural } \\
\end{array}$ \\
\hline $\begin{array}{l}\text { Inicio } \\
\text { siglo XX }\end{array}$ & \begin{tabular}{|l|}
$\begin{array}{l}\text { Geddes } \\
(1960)\end{array}$ \\
\end{tabular} & & \\
\hline $\begin{array}{l}\text { Segunda } \\
\text { mitad } \\
\text { siglo XX }\end{array}$ & $\begin{array}{l}\text { McHarg } \\
(2000) \\
\text { Olgyay } \\
(1998)\end{array}$ & $\begin{array}{l}\text { Lynch (1998), } \\
\text { Cullen (1974), Tuan } \\
\text { (2007), Bailly (1978) }\end{array}$ & Geertz (1973) \\
\hline $\begin{array}{l}\text { Finales } \\
\text { siglo XX e } \\
\text { inicio siglo } \\
\text { XXI }\end{array}$ & $\begin{array}{l}\text { Fariña } \\
\text { (2007), } \\
\text { Higueras } \\
(2012)\end{array}$ & \begin{tabular}{|l|} 
\\
Maderuelo (2010), \\
Zoido (2012), \\
Thiébaut (2013), \\
Alberto-Villavicencio \\
(2017), D'Hers \\
(2017), Monnet \\
(1995)
\end{tabular} & \begin{tabular}{|l|} 
De Certeau \\
(1996), \\
Giménez \\
(2003), \\
Reguillo \\
(1996), \\
Narváez \\
(2011), Duch \\
(2015), Silva \\
(2006) \\
\end{tabular} \\
\hline
\end{tabular}

Figura 1. Genealogía en el estudio del entorno urbano. Fuente: Elaboración propia.

\section{DISCUSIÓN}

Luego de la revisión de trabajos, puede decirse que, desde los tempranos estudios sobre la ciudad, surgirían directrices que en la actualidad continúan vigentes. Así es como Geddes (1960) propone métodos participativos que involucren a la ciudadanía durante el proceso de planificación urbana y territorial; McHarg (2000) sienta bases conceptuales que luego fundamentarían parte del desarrollo tecnológico en materia de Geografía Urbana; mientras que Olgyay (1998) antepone el enfoque y método científico como medio para adaptar los diseños urbanos y arquitectónicos al entorno físico-climático.

Como reacción a estas posturas rígidas, a partir de la segunda mitad del siglo $\mathrm{XX}$, se comenzaron a generar algunos estudios alternativos sustentados en la fenomenología. Desde allí se reconoce la importancia que juega lo perceptual, lo subjetivo y lo simbólico en la interacción con el entorno, el cual muchas veces es entendido como paisaje, particularmente, como paisaje urbano interiorizado. Así se tiene que, mientras Lynch (1998) se interesa en describir la imaginabilidad de la ciudad, Bailly va más allá al afirmar que los aspectos subjetivos del entorno habrán de analizarse, "a fondo, si queremos comprender [y no sólo describir] la 'imagen de la ciudad”" (1978: 17-21).

Al igual que Lynch (1998), Cullen (1974) también se refiere a la imagen, aunque con mayor énfasis en el factor estético. Sin embargo, la diferencia fundamental entre ambos autores es que Lynch (1998), de modo similar a Geddes (1960), idealiza una imagen ordenada, canónica y universal de la ciudad, mientras que Cullen (1974), contrariamente, propone conservar las imágenes y formas identitarias y con "encanto", independientemente de que cumplan o no con determinados cánones estéticos. Se puede decir que Lynch (1998) propugna por un paisaje 
urbano diseñado a modo, sin importar que se trate de un artificio, mientras que Cullen (1974) aboga por los paisajes comunes, ordinarios y cotidianos, conformados y consolidados con el paso del tiempo.

Cuando la relación con el entorno además de utilitaria es simbólica, Cullen (1974) y Bailly (1978) aluden al sentido de lugar, mientras Tuan (2007) refiere a la topofilia. Es el "lazo afectivo" (Tuan, 2007) o "estructura del mundo subjetivo" (Cullen, 1974), que puede ser develada a partir de las sensaciones, percepciones y valoraciones que se hacen del entorno; sin embargo, aunque los autores manifiestan estudiar dichas percepciones, estas se concretan a las propias y no necesariamente a las experimentadas por los habitantes de la ciudad, lo cual también sucede con Careri (2013).

Para superar este faltante, autores provenientes de la Geografía Humana enfocan sus estudios en la dimensión significante del entorno, a partir de las percepciones que experimentan los sujetos. D’Hers (2017) hace una comparación entre lo natural y lo cultural que se presenta en la ciudad; Thiébaut (2013) y Alberto-Villavicencio (2017) consideran al entorno como paisaje cultural; mientras Maderuelo (2010) y Zoido (2012) acotan sus trabajos al paisaje urbano. Todos coinciden en el estudio del espacio vivido, la memoria y las emociones, además del análisis de los usos y prácticas sociales en el paisaje. Thiébaut (2013) y AlbertoVillavicencio (2017), en particular, ponderan la inmersión histórica como medio para conocer de qué forma los cambios en el paisaje repercuten en las percepciones y valoraciones que se hacen en el presente.

Como parte de esta tendencia hacia la interdisciplinariedad, en las últimas décadas, los estudios del entorno urbano han abrevado de la Antropología y la Etnografía, pues con los recursos teóricos y metodológicos que aportan, es posible hacer interpretaciones de los grupos sociales y su cultura. Geertz (1973), por ejemplo, hace descripciones densas sobre las personas y sus interacciones, pero no abunda acerca del papel que juega el entorno físico en esta conformación sociocultural. De manera similar, para Reguillo (1996), la ciudad es un contenedor donde acontecen fenómenos y, por lo tanto, más que de la ciudad, lo que la autora estudia es la dimensión simbólica en la ciudad.

Giménez (2003) va más allá y destaca la relación que existe entre el entorno físico y la conformación de la identidad, pues afirma que cuando ésta se establece, aquel se transmuta en un entorno cultural e identitario. Duch (2015) también analiza esta relación, pero a diferencia de Giménez (2003), lo hace específicamente en la ciudad bajo la consideración, tanto de la componente material como inmaterial. Esto último, lo inmaterial e intangible que va más allá de la materialidad de la ciudad, tiene que ver con lo imaginario; con los imaginarios urbanos que refiere Silva (2006).

En esta relación con el entorno, De Certeau (1996) analiza con profusión las prácticas espaciales, particularmente las "tácticas", es decir, las prácticas no previstas por los planificadores, pero que cotidianamente las personas implementan como mecanismo de adaptación y supervivencia. Sin nombrarlas como tal, las tácticas también son analizadas por Narváez (2011) cuando estudia cualitativamente a la 
ciudad, con los imaginarios y el método etnográfico como medios para comprender la relación, determinista o no, entre las formas sociales y las formas físicas construidas.

Precisamente sobre el determinismo del entorno físico en las conductas de las personas, existen diferencias de opinión entre autores. Por un lado, Geddes (1960) y Lynch (1998) consideran que dicho entorno sí es determinante de las acciones. Lynch (1998), incluso, afirma que las percepciones y conductas de los habitantes pueden ser redirigidas mediante la transformación estético-escenográfica de la ciudad. Es una visión morfológica y esteticista, que en cierta forma también comparte Cullen (1974). Autores como Reguillo (1996), Maderuelo (2010), Thiébaut (2013) o Duch (2015), más que a lo material, atribuyen las conductas y acciones sociales a factores de tipo sociocultural, pues dicen, funcionan como mecanismos mediadores de esta relación entre sociedad y entorno.

Algo común entre algunos autores es la crítica hacia las políticas urbanas que omiten la opinión de los habitantes. Geddes (1960) es de los primeros que hacen este tipo de observaciones; Cullen (1974) arremete contra la tradición canónica y dogmática bajo la cual se ha planificado a la ciudad; Careri (2013) dirige su reproche hacia los tecnócratas de escritorio quienes, dice, intervienen la ciudad sin antes conocerla a ras de suelo; De Certeau (1996) resalta la acción de las personas comunes, que se ven obligadas a adaptarse como una manera de contrarrestar las poco asertivas iniciativas generadas por los especialistas; mientras que Silva (2006), al igual que Reguillo (1996) y su propuesta de saberes comunes, destaca las verdades sociales, incluso imaginarias, pero no por ello inexistentes, aunque más importantes que las verdades de los tecnócratas de la ciudad.

Finalmente debe considerarse la crítica que hace Serra (1998), acerca del método científico y los criterios bioclimáticos como únicos medios para planificar la ciudad y hacer arquitectura pues, afirma, se trata de directrices "demasiado rígidas para la complejidad de la arquitectura real” (Serra, 1998: VII). Es una reflexión extrapolable hacia aquellas propuestas cientificistas y universalistas que dejan fuera la subjetividad y la complejidad de los individuos, y que consideran a la sociedad como un bloque homogéneo y a la ciudad como un objeto susceptible de ser intervenido tan sólo a partir de criterios técnicos.

\section{CONCLUSIONES}

De acuerdo con el análisis que se ha realizado, se puede afirmar que la genealogía en los estudios de la ciudad y su entorno es poco definida. Aunque el objeto reclama interdisciplinariedad, es precisamente el cruce y triangulación de métodos y técnicas de investigación lo que dificulta una clasificación debido a que la variable referencial -sea el objeto, los objetivos o, incluso, las herramientas-, no necesariamente es coincidente con la postura o base teórica que anuncian. A pesar de ello, como primera 
propuesta, se ha creído conveniente presentar los estudios en los tres grupos ya definidos de acuerdo con sus temáticas y enfoques particulares.

Respecto a su episteme, teorías y métodos, el avance en estos estudios tampoco ha sido lineal. Sin embargo, como una segunda propuesta, se advierte un tránsito en los planteamientos, algunas veces coincidentes y otras excluyentes, pudiendo clasificarse en tres momentos: el primero se refiere a los estudios preliminares, racionales y deductivos, que surgen como reducto del siglo XIX; el segundo abarca las propuestas fenomenológicas, hermenéuticas e inductivas, originadas durante la segunda mitad del siglo XX, en las cuales los significados se realizan a partir de las percepciones individuales; mientras el tercer momento comprende los aportes interdisciplinares que se han hecho desde finales del siglo pasado, cuya base epistémica, no siempre estable, en determinada proporción es tanto inductiva como deductiva. En cualquiera de ellos, la experiencia urbana, como herramienta de significados, procura dejar fuera el etnocentrismo y se construye colectivamente a partir de la suma de individualidades y de percepciones que van más allá de lo óptico y lo háptico.

Una tercera reflexión puede hacerse en función del origen disciplinar de los trabajos y el énfasis que hacen en el objeto. Así se tiene que las propuestas generadas desde la Arquitectura y el Urbanismo, aunque en general consideran lo social, su prioridad es el estudio de la materialidad y funcionalidad de la ciudad. En otra posición se encuentran los aportes provenientes de la Antropología Cultural, que si bien reconocen la importancia del entorno físico, su principal interés son las relaciones sociales y la producción cultural, con la ciudad como mero soporte de esa materialidad. Mientras que, en una posición más moderada, bajo los aportes de la Geografía Humana, se aprecia un balance en el estudio de la relación entre la sociedad y el espacio físico, así como entre lo natural y lo cultural del entorno, que es entendido como paisaje. Derivado de lo anterior, una cuarta reflexión refiere a la factibilidad y pertinencia de estudiar la ciudad y su entorno desde nuevas aproximaciones interdisciplinares, cuyos cruces metodológicos posibilitan el acceso a renovadas explicaciones y comprensiones de la realidad social y urbana; sin embargo, esta diversidad de propuestas puede resultar ilusoria.

Un último punto tiene que ver con que las epistemes, teorías y métodos tienden a asemejarse entre sí. Ello puede deberse a que, aun sin proponérselo, todos los referentes notoriamente han repetido lo que Geddes ya afirmaba hace más de un siglo: que la dicotomía en tensión del campo-ciudad, argumentada desde la postura dialéctica, es desechada; que el entorno urbano es simultáneamente condicionado y condicionante, por lo que, la ciudad y su región están en interacción y complementariedad, y no en contradicción; que a la gestión, estudio y planeamiento de las ciudades se le otorga el estatuto de ciencia: la urbanística; y, finalmente, que lo interpretativo, lo colectivo y lo multidisciplinario no sólo es fundamental, sino lo adecuado. 
Así que quizá siga siendo válido parafrasear a Freud en el sentido de que, origen es destino, y en los fenómenos urbanos -y su abordaje-, visto lo visto, nunca estará, mejor dicho.

\section{FUENTES DE CONSULTA}

Alberto-Villavicencio, A. (2017), "Configuración del paisaje a partir de la memoria de los ciudadanos: el caso de La Piedad, Michoacán (1940-2016)", en Naturaleza, territorio y ciudad en un mundo global. Actas del XXV Congreso de la AGE, AGE/Universidad Autónoma de Madrid, España, pp. 33-42.

Aymonino, C. (1971), Orígenes y desarrollo de la ciudad moderna, Gustavo Gili, España.

Bailly, A. (1978), La percepción del espacio urbano. Conceptos, métodos de estudio y su utilización en la investigación urbanística, Instituto de Estudios de Administración Local, España.

Bassol, M. (1988), Antología de sociología Urbana, UNAM, México.

Bettin, G. (1983), Los Sociólogos de la ciudad, Gustavo Gili, España.

Bochensky, I. (1997), La Filosofía Actual, Fondo de Cultura Económica, México.

Careri, F. (2013), Walkscapes. El andar como práctica estética, Gustavo Gili, España.

Collins, R. (1996), Cuatro tradiciones sociológicas, UNAM, México.

Cucó, J. (2014), Antropología urbana, Ariel, España.

Cullen, G. (1974), El paisaje urbano. Tratado de estética urbanística, BLUME, España.

De Certeau, M. (1996), La invención de lo cotidiano. 1: Artes de hacer, Universidad Iberoamericana/ITESO, México.

D’Hers, M.V. (2017), “De la montaña natural a la montaña humanizada: estudio antropológico de la relación entre la ciudad de Caracas y El Ávila", en Naturaleza, territorio y ciudad en un mundo global. Actas del XXV Congreso de la AGE, AGE/Universidad Autónoma de Madrid, España, pp. 1754-1762.

Duch, L. (2015), Antropología de la ciudad, Herder, España.

Fariña, J. (2007), La ciudad y el medio natural, Akal, España.

Flores, C. (2015a), Ciudad, Arquitectura y Sociedad. El movimiento moderno en Tepic. Parte II: Urbanística y Urbanización, UAN-UAS, México.

Flores, C. (2015b), "La marginalidad y la termodinámica como mímesis de la urbanística", en Nóesis. Revista de Ciencias Sociales y Humanidades, núm. 47-2, vol. 24, pp. 76-93. Disponible en http://www.redalyc.org/ articulo.oa?id=859/85939869006, consultado el 13 de septiembre de 2019.

García, A. (2014), "La territorialización en el análisis sociológico", en Hugo Suárez (comp.), Sociólogos y su sociología. Experiencias en el ejercicio del oficio en México", UNAM, México, pp. 267-326.

García, C. (2016), Teorías e historia de la ciudad contemporánea, Gustavo Gili, España.

Geertz, C. (1973), La interpretación de las culturas, Gedisa, España. 
Geddes, P. (1960), Ciudades en evolución, Infinito, Argentina.

Giménez, G. (2003), La Cultura como Identidad y la Identidad como Cultura, UNAM, México.

Hiernaux, D. (2010), "La geografía hoy: Giros, fragmentos y nueva unidad”, en Alicia Lindón y Daniel Hiernaux (dir.), Los giros de la geografía humana: desafíos y horizontes, Anthropos/UAM, México.

Higueras, E. (2012), Urbanismo bioclimático, Gustavo Gili, España.

Lynch, K. (1998), La imagen de la ciudad, Gustavo Gili, España.

Maderuelo, J. (2010), “El paisaje urbano”, Revista Estudios Geográficos, núm. 269 , vol. 71, pp. 575-600.

Mardones, J. (2003), Filosofía de las ciencias humanas y sociales. Materiales para una fundamentación científica, Anthropos, España.

McHarg, I. (2000), Proyectar con la naturaleza, Gustavo Gili, España.

Monnet, J. (1995), Usos e imágenes del centro histórico de la ciudad de México, Centro de Estudios mexicanos y centroamericanos, México

Narváez, A. (2011), Etnografía para la investigación en arquitectura y urbanismo, UANL, México.

Norberg-Schulz, C. (1976), Genius Loci. Towards a Phenomenology of Architecture, Rizzoli, Estados Unidos de Norteamérica.

Olgyay, V. (1998), Arquitectura y clima, Gustavo Gili, España.

Ramos, R. (2018), "Del extralocus al intralocus. Imágenes, imaginarios e imaginerías en las representaciones urbanas del Tepic preliberal”, en José Luis Quintero (coodr.), Ciencias sociales y diálogo de saberes: perspectivas y entrecruces, Ediciones del Lirio/UAN, pp. 215-245.

Reguillo, R. (1996), La construcción simbólica de la ciudad, ITESO/UP, México.

Rossi, A. (1981), La arquitectura de la ciudad, Gustavo Gili, España.

Ruiz, S. J. (2000), Complejidad urbana y determinación. Estructuras comunicativas y planeamiento urbano en el desarrollo del Área Metropolitana de Madrid, BOE/Universidad Carlos III, España.

Serra, R. (1998), Prefacio en Víctor Olgyay, Arquitectura y clima, Gustavo Gili, España.

Sica, P. (1980), Historia del Urbanismo. El siglo XIX-2, IEAL, España.

Silva, A. (2006), Imaginarios urbanos, Arango Editores, Colombia.

Souto, P. (2011), "El concepto de paisaje. Significados y usos en la geografía contemporánea”, en Patricia Souto (coord.), Territorio, lugar, paisaje. Prácticas y conceptos básicos en geografía, EFFL, Argentina.

Terán, F. (1985), El problema urbano, Salvat, España.

Thiébaut, V. (2013), "Paisaje e identidad. El río Papaloapan, elemento funcional y simbólico de los paisajes del sotavento", Revista LiminaR. Estudios Sociales y Humanísticos, núm. 2, vol. 11, pp. 82-99.

Tuan, Y. (2007), Topofilia. Un estudio de las percepciones, actitudes y valores sobre el entorno, Melusina, España.

Urrutia, V. (1999), Para entender qué es la ciudad. Teorías sociales, EVD, España.

Wallerstein, I. (2007), Impensar las ciencias sociales: límites de los paradigmas decimonónicos, Siglo XXI, México. 
Zoido, F. (2012), “Paisaje urbano. Aportaciones para la definición de un marco teórico, conceptual y metodológico", en Carmen Delgado, Joseba Juaristi y Sergio Tomé, Ciudades y paisajes urbanos en el siglo XXI, Santander Librería Estudio, España.

\section{Notas}

[1] El presente trabajo se desprende de los resultados preliminares del Estado de la Cuestión de la Tesis Doctoral que desarrolla el autor en el programa de Doctorado en Ciencias Sociales de la Universidad Autónoma de Nayarit. 